九州大学学術情報リポジトリ

Kyushu University Institutional Repository

\title{
Development of a Procedure to Measure the Structure of a Plant Community Using Stereo Images Taken by Two Digital Cameras
}

Haraguchi, Tomokazu

Institute of Tropical Agriculture, Kyushu University

Hirota, 0samu

Institute of Tropical Agriculture, Kyushu University

Ahmed, Faruque

Division of Tropical Crops and Environment, Department of Plant Resources, Graduate School of Bioresource and Bioenvironmental Sciences, Kyushu University

https://doi.org/10.5109/24389

出版情報: 九州大学大学院農学研究院紀要. 45 (2)，pp.405-413，2001-02-28. Kyushu University バージョン：

権利関係 : 


\title{
Development of a Procedure to Measure the Structure of a Plant Community Using Stereo Images Taken by Two Digital Cameras
}

\author{
Tomokazu Haraguchi**, Osamu Hirota and Faruque Ahmed* \\ Institute of Tropical Agriculture, Kyushu University, Fukuoka 812-8581, Japan \\ (Received October 27, 2000 and accepted November 10, 2000)
}

\begin{abstract}
For the estimation of production or evapotranspiration of a plant community, the spatial structure of plants, especially the geometry of the leaves, has to be known. The geometry of leaves is defined by the shape, the area and the position of each leaf. It is known that the area of a leaflet of beans can be estimated by the lengths of the long and short axes of a leaflet. Two images were taken at the same time by two cameras, which were set at different positions, in a mungbean field. The spatial coordinates of four points, which determine the long and short axes of a leaflet, were estimated by the analysis of the stereo images.
\end{abstract}

\section{INTRODUCTION}

It is possible to estimate the amount of products or photosynthesis of a whole plant community with the photosynthetically active radiation intercepted by leaves. Evapotranspiration from vegetation is greatly affected by net radiation. Solar radiation accounts for most of the net radiation during the daytime when evapotranspiration is large. Evapotranspiration consists of transpiration from plants and evaporation from the soil surface. Transpiration is affected by solar radiation intercepted by a canopy, while evaporation originated from the soil surface is able to be related to solar radiation which reachs to the soil surface passing through a canopy. Therefore, it is important to understand the spatial structure of plants, especially the geometry of leaves for the estimation of production or evapotranspiration of a plant community.

The geometry of leaves is defined by the shape, the area and the position of each leaf. Hirota and Nakano (2000) measured the spatial positions of soybean leaflets using a manipulator. It takes a lot of time to measure the structure of a plant community in the field with this equipment.

Recently, equipment for photographing and recording have been digitized, and so the prediction of the three dimensional structure of objects from two dimension images using image analysis has been applied to various fields (e.g. Ruff et al. (1995), Burie et al. (1995)). Shibayama et al. (1989) estimated the spatial structure of a plant community using an ITV camera, a laser beam scanner, a video processor and a desktop computer, however there are some problems when using this equipment in the field.

In this study the procedure used to easily measure the spatial structure of a plant community in the field by the analysis of stereo images was proposed, and then the spatial

\footnotetext{
* Division of Tropical Crops and Environment, Department of Plant Resources, Graduate School of Bioresource and Bioenvironmental Sciences, Kyushu University

** Corresponding author (E-mail: thara@agr.kyushu-u.ac.jp)
} 
coordinates of four points, which express the shape of the leaflets, were estimated by this procedure.

\section{PRINCIPLES}

\section{Camera coordinate system and world coordinate system}

The coordinate system based on the position, where a camera is set, is called the camera coordinate system. On a camera coordinate system, usually, a picture plane is taken as the $x-y$ coordinate plane and the direction of the camera is taken as the $z$ coordinate axis. In this paper, the following camera coordinate system is considered.

- The normal vector of the screen is the same as the $z$-axis of the camera coordinate system.

- The directions of the $x$-axis and the $y$-axis are in the directions of rightward and downward of the camera, respectively.

- The direction of the camera agrees with the positive side of the $z$-axis. An increased $z$-value indicates more distance from the camera.

Camera coordinate systems change with the setting position and the direction of the cameras. For the purpose of treating objects expressed in some camera coordinate systems synthetically, putting them in a unified coordinate system called a world coordinate system is needed.

\section{Central projection}

The coordinates of point $\mathrm{A}^{\prime}$, which is the central projection of a point $\mathrm{A}\left(x_{A}, y_{A}, z_{A}\right)$ onto the plane $\mathrm{S}$ parallel to the $x-y$ plane, is given,

$$
\left(x_{A}^{\prime}, y_{A}^{\prime}, z_{A}^{\prime}\right)=\left(\frac{z_{s}}{z_{A}} x_{A}, \frac{z_{S}}{z_{A}} y_{A}, z_{s}\right)
$$

where $z_{s}$ is a $z$-value of the plane S.

Let the points, which are the central projection on the plane $S$ of three points $A, B$ and $\mathrm{C}$, be $\mathrm{A}^{\prime}, \mathrm{B}^{\prime}$ and $\mathrm{C}^{\prime}$, respectively, and the points, which are images of the three points $\mathrm{A}, \mathrm{B}$ and $\mathrm{C}$ on the image taken with a camera, be $\mathrm{A}^{\prime \prime}, \mathrm{B}^{\prime \prime}$ and $\mathrm{C}^{\prime \prime}$, respectively. Triangle $\mathrm{A}^{\prime} \mathrm{B}^{\prime} \mathrm{C}^{\prime}$ on the plane $\mathrm{S}$ is similar to triangle $\mathrm{A}^{\prime \prime} \mathrm{B}^{\prime \prime} \mathrm{C}^{\prime \prime}$ on the image. The following equations apply to these triangles,

$$
\begin{aligned}
& \cos \theta_{1}=\frac{\overrightarrow{\mathrm{AB}^{\prime}} \cdot \overrightarrow{\mathrm{A}^{\prime} \mathrm{C}^{\prime}}}{\left|\overrightarrow{\mathrm{A \textrm {B } ^ { \prime }}}\right|\left|\overrightarrow{\mathrm{A}^{\prime} \mathrm{C}^{\prime}}\right|}=\frac{\overrightarrow{\mathrm{A}^{\prime \prime} \mathrm{B}^{\prime \prime}} \cdot \overrightarrow{\mathrm{A}^{\prime \prime} \mathrm{C}^{\prime \prime}}}{\left|\overrightarrow{\mathrm{A}^{\prime} \mathrm{B}^{\prime \prime}}\right|\left|\overrightarrow{\mathrm{A}^{\prime \prime} \mathrm{C}^{\prime \prime}}\right|} \\
& \cos \theta_{2}=\frac{\overrightarrow{\mathrm{B}^{\prime} \mathrm{A}^{\prime}} \cdot \overrightarrow{\mathrm{B}^{\prime} \mathrm{C}^{\prime}}}{\left|\overrightarrow{\mathrm{B}^{\prime}}\right|\left|\overrightarrow{\mathrm{B}^{\prime} \mathrm{C}^{\prime}}\right|}=\frac{\overrightarrow{\mathrm{B}^{\prime \prime} \mathrm{A}^{\prime \prime}} \cdot \overrightarrow{\mathrm{B}^{\prime \prime} \mathrm{C}^{\prime \prime}}}{\left|\overrightarrow{\mathrm{B}^{\prime \prime} \mathrm{A}^{\prime \prime}}\right|\left|\overrightarrow{\mathrm{B}^{\prime \prime} \mathrm{C}^{\prime \prime}}\right|} \\
& \cos \theta_{3}=\frac{\overrightarrow{\mathrm{C}^{\prime} \mathrm{A}^{\prime}} \cdot \overrightarrow{\mathrm{C}^{\prime}}}{\left|\overrightarrow{\mathrm{C}^{\prime} \mathrm{A}}\right||\overrightarrow{\mathrm{C}}|}=\frac{\overrightarrow{\mathrm{C}^{\prime \prime}} \mid}{\left|\overrightarrow{\mathrm{C}^{\prime \prime}} \cdot \overrightarrow{\mathrm{C}^{\prime \prime}}\right|\left|\overrightarrow{\mathrm{C}^{\prime \prime} \mathrm{B}^{\prime \prime}}\right|}
\end{aligned}
$$

where $\theta_{1}, \theta_{2}$ and $\theta_{3}$ are the measures of angles $\mathrm{B}^{\prime} \mathrm{A}^{\prime} \mathrm{C}^{\prime}, \mathrm{C}^{\prime} \mathrm{B}^{\prime} \mathrm{A}^{\prime}$ and $\mathrm{A}^{\prime} \mathrm{C}^{\prime} \mathrm{B}^{\prime}$, respectively. Using the coordinates of these points equations (2), (3) and (4) can be expressed as 


$$
\begin{aligned}
& \frac{\left(x_{B}^{\prime}-x_{A}^{\prime}\right)\left(x_{C}^{\prime}-x_{A}^{\prime}\right)+\left(y_{B}^{\prime}-y_{A}^{\prime}\right)\left(y_{C}^{\prime}-y_{A}^{\prime}\right)}{\sqrt{\left(x_{B}^{\prime}-x_{A}^{\prime}\right)^{2}+\left(y_{B}^{\prime}-y_{A}^{\prime}\right)^{2}} \sqrt{\left(x_{C}^{\prime}-x_{A}^{\prime}\right)^{2}+\left(y_{C}^{\prime}-y_{A}^{\prime}\right)^{2}}}
\end{aligned}
$$

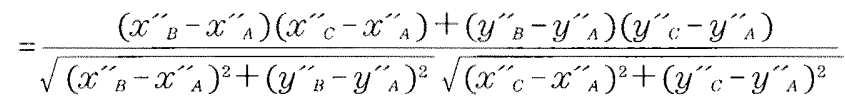

$$
\begin{aligned}
& \frac{\left(x_{A}^{\prime}-x_{B}^{\prime}\right)\left(x_{C}^{\prime}-x_{B}^{\prime}\right)+\left(y_{A}^{\prime}-y_{B}^{\prime}\right)\left(y_{C}^{\prime}-y_{B}^{\prime}\right)}{\sqrt{\left(x_{A}^{\prime}-x_{B}^{\prime}\right)^{2}+\left(y_{A}^{\prime}-y_{B}^{\prime}\right)^{2}} \sqrt{\left(x_{C}^{\prime}-x_{B}^{\prime}\right)^{2}+\left(y_{C}^{\prime}-y_{B}^{\prime}\right)^{2}}} \\
& =\frac{\left(x_{A}^{\prime \prime}-x_{B}^{\prime \prime}\right)\left(x_{C}^{\prime \prime}-x_{B}^{\prime \prime}\right)+\left(y_{A}^{\prime \prime}-y_{B}^{\prime \prime}\right)\left(y_{C}^{\prime \prime}-y_{B}^{\prime \prime}\right)}{\sqrt{\left(x_{A}^{\prime \prime}-x_{B}^{\prime \prime}\right)^{2}+\left(y^{\prime \prime}{ }_{A}-y^{\prime \prime}\right)^{2}} \sqrt{\left(x^{\prime \prime} C_{C}-x^{\prime \prime}{ }_{B}\right)^{2}+\left(y_{C}^{\prime \prime}-y_{B}^{\prime \prime}\right)^{2}}} \\
& \frac{\left(x_{A}^{\prime}-x_{C}^{\prime}\right)\left(x_{B}^{\prime}-x_{C}^{\prime}\right)+\left(y_{A}^{\prime}-y_{C}^{\prime}\right)\left(y_{B}^{\prime}-y_{C}^{\prime}\right)}{\sqrt{\left(x_{A}^{\prime}-x_{C}^{\prime}\right)^{2}+\left(y_{A}^{\prime}-y_{C}^{\prime}\right)^{2}} \sqrt{\left(x_{B}^{\prime}-x_{C}^{\prime}\right)^{2}+\left(y_{B}^{\prime}-y_{C}^{\prime}\right)^{2}}}
\end{aligned}
$$

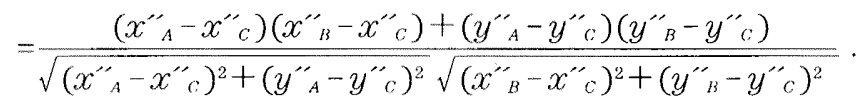

Furthermore, the following relationship equation applies to the triangles,

$$
\frac{\left|\overrightarrow{\mathrm{B}^{\prime} \mathrm{C}^{\prime}}\right|}{\sin \theta_{1}}=\frac{\left|\overrightarrow{\mathrm{C}^{\prime}} \mathrm{A}^{\prime}\right|}{\sin \theta_{2}}=\frac{\left|\overrightarrow{\mathrm{A}^{\prime}}\right|}{\sin \theta_{3}}
$$

\section{ANALYSIS OF IMAGES}

\section{Photography}

An equipment consists of two digital cameras, two poles as bases and the frame was established in an experimental plot (Fig. 1). Each digital camera was attached on the

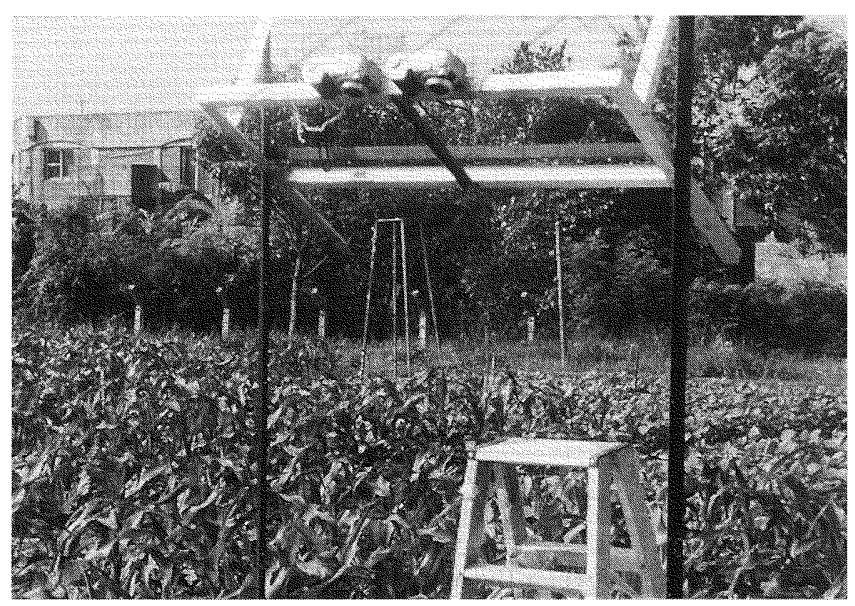

Fig. 1. Photographing system. 
frame with a screw for fixing the camera angle. The photography was conducted in the procedure as is shown below.

1. Signs were marked on four points, which determine the lengths of the long and short axes of each leaf on the top of a canopy

2. The shutters of the cameras were released at the same time to avoid gaps of a leaf's position, which are influenced by the wind

3. The leaves on the top of the canopy were cut, which were already photographed, in order to photograph the leaves in the next layer

This procedure was repeated until there were no more leaves.

Set the point, where the support on the left side of the equipment is in contact with the soil surface, to the origin of the world coordinate system, and then the following relationship equation is applied between the world coordinate system and the camera coordinate system (Fig. 2)

$$
\left(\begin{array}{l}
\mathrm{X} \\
\mathrm{Y} \\
\mathrm{Z}
\end{array}\right)=\left(\begin{array}{l}
X O-x_{0}+x \\
\left(L+y_{0}-y\right) \cos \theta+\left(z+z_{0}\right) \sin \theta \\
Z O+\left(L+y_{0}-y\right) \sin \theta-\left(z+z_{0}\right) \cos \theta
\end{array}\right)
$$

where $L$ is the length of the arm, $Z O$ is the vertical distance from the origin of the world coordinate system to the connection point, where the arm joins with the support, $X O$ is the horizontal distance between the origin and the point, where the camera is in contact with the equipment, $x_{0}, y_{0}$ and $z_{0}$ are the lengths which express the relationship between the point, where the camera comes into contact with the equipment, and the point of sight and $\theta$ is the measure of the angle of the elevation of the arm.

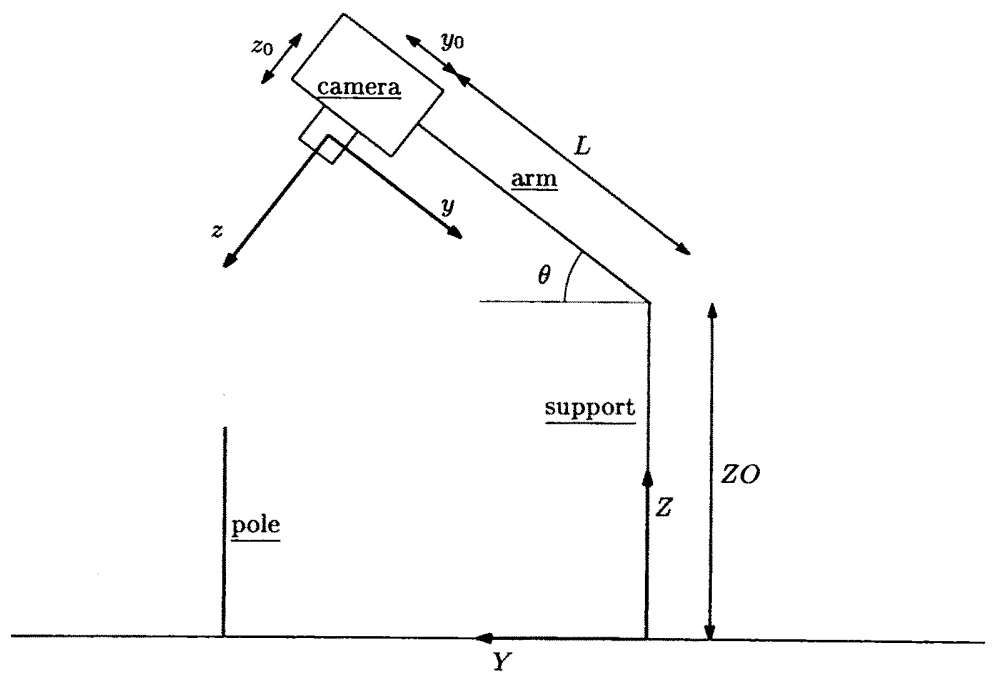

Fig. 2. Relationship between the world coordinate system and the camera coordinate system. 


\section{Image Analysis}

The analysis of the images was conducted in the procedure as shown below.

(1) The coordinates of three points $\mathrm{A} 1^{\prime \prime}, \mathrm{B1}$ " and $\mathrm{C1}$ " (i.e. the images of the tips of the two poles, $\mathrm{A}$ and $\mathrm{B}$, and a point on a leaf, $\mathrm{C}$ ) on the picture taken by the camera which has the point of sight $\mathrm{P} 1$ were read.

(2) The coordinates of the points $\mathrm{Al}^{\prime}$ and $\mathrm{B1}^{\prime}$ were calculated, which are the central projection of the points $\mathrm{A}$ and $\mathrm{B}$ onto the plane $\mathrm{S}$, by eq. (1) as the $z$-coordinate is $z_{s}$,

$$
\begin{aligned}
& \left(x_{A l}^{\prime}, y_{A l}^{\prime}, z_{A I}^{\prime}\right)=\left(\frac{z_{s}}{z_{A}} x_{A}, \frac{z_{s}}{z_{A}} y_{A}, z_{s}\right) \\
& \left(x_{B l}^{\prime}, y_{B l}^{\prime}, z_{B I}^{\prime}\right)=\left(\frac{z_{s}}{z_{B}} x_{B}, \frac{z_{s}}{z_{B}} y_{B}, z_{s}\right) .
\end{aligned}
$$

(3) The coordinates of point $\mathrm{Cl}^{\prime}$ were determined, which is the central projection of point $\mathrm{C}$, using the relationship equation, which is applied between the triangle $\mathrm{A} 1^{\prime} \mathrm{B1}^{\prime} \mathrm{C} 1^{\prime}$ and the triangle $\mathrm{A} 1$ " $\mathrm{B} 1$ " $\mathrm{C} 1$ ". The following calculation is made in detail.

The values of $\cos \theta_{1}, \cos \theta_{2}$ and $\cos \theta_{3}$ are obtained by substituting coordinates of points $\mathrm{Al}^{\prime \prime}, \mathrm{Bl}^{\prime \prime}$ and $\mathrm{C1}$ " into equations (2),(3) and (4). By substituting these values into the equation, $\sin ^{2} \theta+\sin ^{2} \theta=1$, the values of $\sin \theta_{1}, \sin \theta_{2}$ and $\sin \theta_{3}$ are calculated. The magnitude of the vector $\overline{\mathrm{A} 1^{\prime} \mathrm{B} 1}{ }^{\prime}$ is obtained with the coordinates of the points $\mathrm{A} 1^{\prime}$ and $\mathrm{B} 1^{\prime}$. By substituting this value into equation (8) the magnitude of the vectors $\overline{B 1^{\prime}}{ }^{\prime} 1^{\prime}$ and ${\widehat{C} 1^{\prime} A{ }^{\prime}}^{\prime}$ are determined. Substituting these values into equations (5) and (6) the following equations are obtained,

$$
\begin{aligned}
& f x_{c 1}^{\prime}+g y_{C 1}^{\prime}+h=0 \\
& u x_{C 1}^{\prime}+u y_{C 1}^{\prime}+w=0
\end{aligned}
$$

where

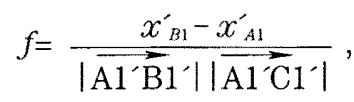

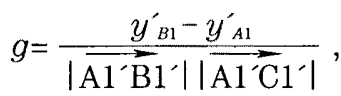

$$
\begin{aligned}
& h=-\frac{x_{A 1}^{\prime}\left(x_{B 1}^{\prime}-x_{A 1}^{\prime}\right)+y_{A 1}^{\prime}\left(y_{B 1}^{\prime}-y_{A 1}^{\prime}\right)}{\left|\vec{A} 1^{\prime} \vec{B} 1^{\prime}\right|\left|\overrightarrow{\mathrm{A}^{\prime} \overparen{C} 1}\right|}-\cos \theta_{1} \text {, } \\
& u=\frac{x_{A 1}^{\prime}-x_{B 1}^{\prime}}{\left|\overrightarrow{B 1^{\prime} \mathrm{A} 1^{\prime}}\right|\left|\overrightarrow{\mathrm{B}^{\prime} \mathrm{C} 1^{\prime}}\right|}, \\
& v=\frac{\bar{y}_{A 1}^{\prime}-y_{B 1}^{\prime}}{\left|\overline{\mathrm{B} 1^{\prime} \mathrm{A} 1^{\prime}}\right|\left|\overrightarrow{\mathrm{B} 1^{\prime} \mathrm{C} 1^{\prime}}\right|}
\end{aligned}
$$

and

$$
w=-\frac{x_{B 1}^{\prime}\left(x_{A 1}^{\prime}-x_{B 1}^{\prime}\right)+y_{B 1}^{\prime}\left(y_{A 1}^{\prime}-y_{B 1}^{\prime}\right)}{\left|\overline{B 1^{\prime} \mathrm{A} 1^{\prime}}\right| \mid \overrightarrow{\mathrm{B} 1^{\prime} \mathrm{C} 1^{\prime} \mid}}-\cos \theta_{2} .
$$

By solving these simultaneous equations, the coordinates of $\mathrm{C1}^{\prime}$ are determined. 
(4) By performing coordinate transformation, the equation of the line $\mathrm{P}^{\mathrm{C}} \mathrm{Cl}^{\prime}$ on the world coordinate system is obtained.

(5) The equation of the line $\mathrm{P} 2 \mathrm{C}^{\prime}$ ' in the world coordinate system is determined from the image taken by the camera, which has the point of sight $\mathrm{P} 2$, by the same procedure as above.

(6) Let the coordinates of the points of sight P1 and P2 be $\left(X_{P 1}, Y_{P 1}, Z_{P 1}\right)$ and $\left(X_{P 2}, Y_{P 2}, Z_{P 2}\right)$, and the directional vectors of the lines $\mathrm{P} 1 \mathrm{Cl}^{\prime}$ and $\mathrm{P} 2 \mathrm{C} 2^{\prime}$ be $\left(l_{1}, m_{1}, n_{1}\right)$ and $\left(l_{2}, m_{2}, n_{2}\right)$, and then these two lines are expressed by the following equations, respectively,

$$
\begin{aligned}
& \frac{X-X_{P 1}}{l_{1}}=\frac{Y-Y_{P 1}}{m_{1}}=\frac{Z-Z_{P 1}}{n_{1}}=t_{1} \\
& \frac{X-X_{P 2}}{l_{2}}=\frac{Y-Y_{P 2}}{m_{2}}=\frac{Z-Z_{P 2}}{n_{2}}=t_{2} .
\end{aligned}
$$

The distance between a point $\mathrm{C} 1\left(X_{C 1}, Y_{C 1}, Z_{C 1}\right)$ on the line $\mathrm{P} 1 \mathrm{Cl}^{\prime}$ and a point $\mathrm{C} 2\left(X_{C 2}\right.$, $Y_{C 2}, Z_{C 2}$ ) on the line $\mathrm{P} 2 \mathrm{C}^{\prime}$ ' is expressed as

$$
d=\sqrt{\left(X_{C 2}-X_{C 1}\right)^{2}+\left(Y_{C 2}-Y_{C 1}\right)^{2}+\left(Z_{C 2}-Z_{C 1}\right)^{2}}
$$

Taking equations (14) and (15) into account, the coordinates of points $\mathrm{C} 1$ and $\mathrm{C} 2$ are expressed as $\left(X_{C 1}, Y_{C 1}, Z_{C 1}\right)=\left(X_{P_{1}}+l_{1} t_{1}, Y_{P_{1}}+m_{1} t_{1}, Z_{P_{1}}+n_{1} t_{1}\right)$ and $\left(X_{C 2}, Y_{C 2}, Z_{C 2}\right)=\left(X_{P 2}+l_{2} t_{2}\right.$, $\left.Y_{P_{2}}+m_{2} t_{2}, Z_{P_{2}}+n_{2} t_{2}\right)$. Substitute these coordinates into equation (16) and take the square of each side of it,

$$
d^{2}=\left(X_{P 2}+l_{2} t_{2}-X_{P_{1}}-l_{1} t_{1}\right)^{2}+\left(Y_{P 2}+m_{2} t_{2}-Y P_{1}-m_{1} t_{1}\right)^{2}+\left(Z_{P 2}+n_{2} t_{2}-Z_{P_{1}}-n_{1} t_{1}\right)^{2}
$$

The segment $\mathrm{C} 1 \mathrm{C} 2$ is perpendicular to both line $\mathrm{P}^{1} \mathrm{C1}^{\prime}$ and line $\mathrm{P} 2 \mathrm{C} 2^{\prime}$ when the distance between the point $\mathrm{C} 1$ and $\mathrm{C} 2$ becomes minimum, and then the following equations apply,

$$
\begin{aligned}
& l_{1}\left(X_{C 2}-X_{C 1}\right)+m_{1}\left(Y_{C 2}-Y C_{1}\right)+n_{1}\left(Z_{C 2}-Z_{C 1}\right)=0 \\
& l_{2}\left(X_{C 2}-X_{C 1}\right)+m_{2}\left(Y_{C 2}-Y C_{1}\right)+n_{2}\left(Z_{C 2}-Z_{C 1}\right)=0 .
\end{aligned}
$$

If equation (18) is rearranged by substituting the coordinates of the points $\mathrm{C} 1$ and $\mathrm{C} 2$, which expressed with parameters $t_{1}$ and $t_{2}$ respectively, it becomes,

$$
t_{2}=\frac{l_{1}\left(X_{P 1}-X_{P 2}\right)+m_{1}\left(Y_{P 1}-Y_{P 2}\right)+n_{1}\left(Z_{P_{1}}-Z_{P 2}\right)+t_{1}\left(l_{1}^{2}+m_{1}^{2}+n_{1}^{2}\right)}{l_{1} l_{2}+m_{1} m_{2}+n_{1} n_{2}}
$$

Using the parameters $\alpha$ and $\beta$ expressed as

$$
\alpha=\frac{l_{1}^{2}+m_{1}^{2}+n_{1}^{2}}{l_{1} l_{2}+m_{1} m_{2}+n_{1} n_{2}}
$$

and 


$$
\beta=\frac{l_{1}\left(X_{P_{1}}-X_{P 2}\right)+m_{1}\left(Y_{p_{1}}-Y_{P 2}\right)+n_{1}\left(Z_{P_{1}}-Z_{P_{2}}\right)}{l_{1} l_{2}+m_{1} m_{2}+n_{1} n_{2}},
$$

equation(20) becomes $t_{2}=\alpha t_{1}+\beta$. Replacing parameter $t_{2}$ of equation (17) with this equation the following equation is obtained,

$$
d^{2}=a t_{1}^{2}+b t_{\mathrm{i}}+c
$$

where

$$
\begin{aligned}
a= & \left(l_{2} \alpha-l_{1}\right)^{2}+\left(m_{2} \alpha-m_{1}\right)^{2}+\left(n_{2} \alpha-n_{1}\right)^{2} \\
b=2 & \left(X_{P 2}-X_{P 1}+l_{2} \beta\right)\left(l_{2} \alpha-l_{1}\right)+2\left(Y_{P 2}-Y_{P 1}+m_{2} \beta\right)\left(m_{2} \alpha-m_{1}\right) \\
& +2\left(Z_{P 2}-Z_{P 1}+n_{2} \beta\right)\left(n_{2} \alpha-n_{1}\right)
\end{aligned}
$$

and

$$
\mathrm{c}=\left(X_{P^{2}}-X_{P 1}+l_{2} \beta\right)^{2}+\left(Y_{P 2}-Y_{P 1}+m_{2} \beta\right)^{2}+\left(Z_{P 2}-Z_{P^{1}}+n_{2} \beta\right)^{2} .
$$

Differentiating both sides of equation (21) with respect to $t_{1}$, the following equation is obtained

$$
\frac{\mathrm{d} d^{2}}{\mathrm{~d} t_{1}}=2 a t_{1}+\mathrm{b}
$$

The parameter $a$ is greater than or equal to zero, and the value of $d^{2}$ becomes minimum when $\frac{\mathrm{d} d^{2}}{\mathrm{~d} t_{1}}=0$ (i.e. $t_{1}=-\frac{b}{2 a}$ ).

By substituting the parameter $t_{1}$ obtained as above into equation (20) the parameter $t_{2}$ is calculated, and then the coordinates of points $\mathrm{C} 1$ and $\mathrm{C} 2$ are determined. Let the midpoint of segment $\mathrm{C} 1 \mathrm{C} 2$ be point $\mathrm{C}$.

\section{RESULTS AND DISCUSSION}

Photography was conducted in the field planted mungbean. A leaflet was marked at four points, which were the base, $\mathrm{Cb}$, top, $\mathrm{Ct}$, and other two points, where the width of the leaflet was maximum, $\mathrm{Cl}$ and $\mathrm{Cr}$, as shown in Fig. 3. The height of the canopy was about $0.5 \mathrm{~m}$, and then the photography was repeated four times.

An example of a pair of images is shown in Fig. 4. Fig. 4 (a) and (b) were taken by left and right cameras, respectively. The coordinates of the marked point on the world coordinate system were calculated with pairs of pictures. The reading of coordinates of the points on the images taken by digital cameras was carried out by commercial software.

Table 1 shows the results obtained by the analysis of the three numbered leaflets in Fig. 4. The coordinates $(X 1, Y 1, Z 1)$ and $(X 2, Y 2, Z 2)$ correspond to the points $\mathrm{C} 1$ and $\mathrm{C} 2$ in this paper, respectively. For these leaflets, the $x$-coordinates of the points $\mathrm{C} 1$ and $\mathrm{C} 2$ were equal, and the maximum value of differences of the $y$ - and the $z$-coordinates between $\mathrm{C} 1$ and $\mathrm{C} 2$ was $6 \mathrm{~mm}$. For the whole canopy, the maximum value of differences 


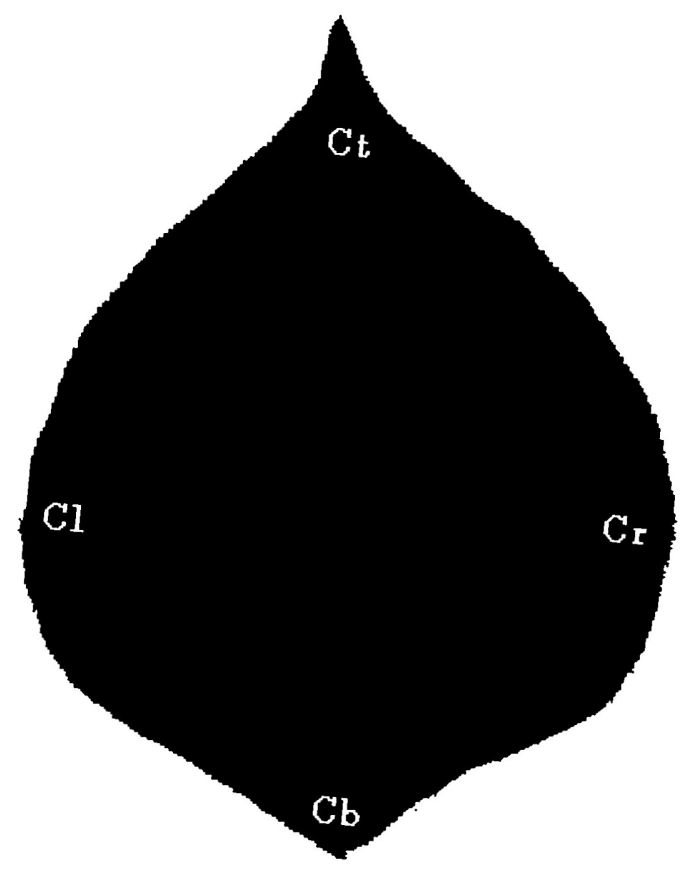

Fig. 3. The marking points on a leaflet.

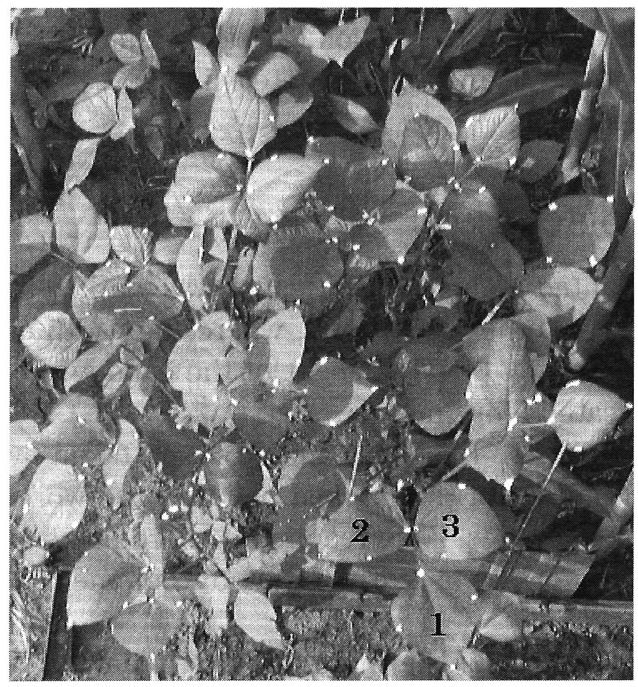

(a)

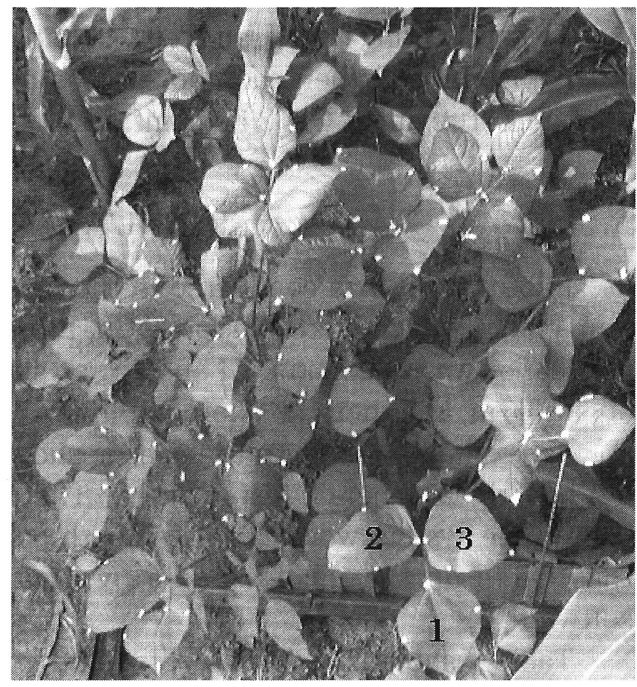

(b)

Fig. 4. Sample of a pair of images. 
Table 1. The spatial coordinates of the points on leaflets 1,2 , and 3 in Fig. 4 . The unit is the $\mathrm{cm}$.

\begin{tabular}{cccccccc}
\hline \multicolumn{1}{c}{ leaflet No. } & $X 1$ & $Y 1$ & $Z 1$ & $X 2$ & $Y 2$ & $Z 2$ \\
\hline 1 & $\mathrm{Cl}$ & 47.2 & 80.6 & 39.3 & 47.2 & 80.8 & 39.3 \\
& $\mathrm{Cr}$ & 39.3 & 78.6 & 35.5 & 39.3 & 79.1 & 35.6 \\
& $\mathrm{Cb}$ & 41.6 & 84.5 & 36.5 & 41.6 & 84.6 & 36.5 \\
& $\mathrm{Ct}$ & 44.8 & 74.6 & 36.1 & 44.8 & 74.7 & 36.1 \\
\hline 2 & $\mathrm{Cl}$ & 36.1 & 85.2 & 37.3 & 36.1 & 85.4 & 37.4 \\
& $\mathrm{Cr}$ & 34.1 & 92.2 & 37.1 & 34.1 & 92.3 & 37.2 \\
& $\mathrm{Cb}$ & 40.4 & 87.8 & 39.1 & 40.4 & 88.0 & 39.2 \\
& $\mathrm{Ct}$ & 30.9 & 86.8 & 34.5 & 30.9 & 86.7 & 34.5 \\
\hline \multirow{2}{*}{3} & $\mathrm{Cl}$ & 45.5 & 91.2 & 42.8 & 45.5 & 91.5 & 43.0 \\
& $\mathrm{Cr}$ & 43.8 & 85.9 & 37.1 & 43.8 & 85.9 & 37.1 \\
& $\mathrm{Cb}$ & 41.1 & 88.1 & 38.9 & 41.1 & 88.4 & 39.0 \\
& $\mathrm{Ct}$ & 50.0 & 85.6 & 41.9 & 50.0 & 86.2 & 42.2 \\
\hline
\end{tabular}

between the coordinates of the points $\mathrm{C} 1$ and $\mathrm{C} 2$ was about $10 \mathrm{~mm}$. These differences might have occured because of a reading error of the coordinates of the points on the leaflets. The signs on the leaflets were circular with a radius of about $3 \mathrm{~mm}$, the read points might differ between a pair of images. To avoid reading errors, the shape or the size of a sign and the way to indicate it should be improved.

If the method of indication is improved so that the four points on a leaflet are able to be clearly photographed, a leaflet's area could be calculated with the lengths of the long and short axes of a leaflet by the method shown by Hirota and Nakano (2000). Then, it would be possible to know the structure of a plant community as a leaf area index and so on by using stereo images taken by two digital cameras.

\section{REFERENCES}

Burie, J. C., J. L. Bruyelle and J. G. Postaire 1995 Detecting and localising obstacles in front of a moving vehicle using linear stereo vision. Mathl. Comput. Modelling, 22(4-7): 235-246

Hirota, O. and Y. Nakano 2000 Modeling of a soybean canopy structure by the approximation of a leaflet into an ellipsoid for estimating direct solar radiation environment. Plant Prod. Sci, 3(1): 67-74

Ruff, B. P., J. A. Marchant and A. R. Frost 1995 Fish sizing and monitoring using a stereo image analysis system applied to fish farming. Aquacultural Engng., 14: 155-173

Shibayama, M., T. Akiyama, T. Watanabe and K. Munakata 1989 Three-dimensional measuring for crop canopies with TV cameras and computer-aided image processing. Bulletin of Green Energy Program Group-Il (Fixation of Matter), 20: 63-86 (in Japanese with an English summary) 